\title{
Predicting bovine milk fat composition using infrared spectroscopy based on milk samples collected in winter and summer
}

\author{
M. J. M. Rutten, ${ }^{* 1}$ H. Bovenhuis, ${ }^{*}$ K. A. Hettinga, $†$ H. J. F. van Valenberg, $†$ and J. A. M. van Arendonk ${ }^{*}$ \\ ${ }^{*}$ Animal Breeding and Genomics Centre, Wageningen University, PO Box 338, 6700 AH Wageningen, the Netherlands \\ †Dairy Science and Technology Group, Wageningen University, PO Box 8129, 6700 EV Wageningen, the Netherlands
}

\begin{abstract}
It has recently been shown that Fourier transform infrared spectroscopy has potential for the prediction of detailed milk fat composition, even based on a limited number of observations. Therefore, there seems to be an opportunity for improvement by means of using more observations. The objective of this study was to verify whether the use of more data would add to the accuracy of predicting milk fat composition. In addition, the effect of season on modeling was quantified because large differences in milk fat composition between winter and summer samples exist. We concluded that the use of 3,622 observations does increase predictability of milk fat composition based on infrared spectroscopy. However, for fatty acids with low concentrations, the use of many observations does not increase predictability to a level at which application of the model becomes obvious. Furthermore, the effect of season on validation r-square was limited but was occasionally large on prediction bias. For fatty acids that show large differences in level and standard deviation between winter and summer, a representative sample that includes observations collected in various seasons is critical for unbiased prediction. This research shows that all major fatty acids, combined groups of fatty acids, and the ratio of saturated to unsaturated fatty acids can be predicted accurately.
\end{abstract}

Key words: milk, fatty acid, mid-infrared, quality

\section{INTRODUCTION}

In many countries, milk fat yield is among the components determining milk price. Therefore, fat percentage is routinely recorded, and fat yield, derived from that, serves as a selection criterion in some dairy breeding programs (Miglior et al., 2005). Routine determination of fat percentage is done by infrared spectroscopy, which has been available for decades (Biggs, 1967) and is highly accurate $\left(\mathrm{r}^{2}>0.996\right.$; Foss, 2009). Today, stan-

Received June 5, 2009.

Accepted September 1, 2009.

${ }^{1}$ Corresponding author: marc.rutten@wur.nl dard automated equipment is commercially available to serve this purpose. To our knowledge, however, no detailed information on milk fat composition is routinely collected.

Milk fat composition is of importance to human health (German et al., 2009) and might also provide information on the health status of a cow (Van Haelst et al., 2008). Bovine milk fat consists of approximately 2.8 times as much saturated fatty acids as unsaturated fatty acids (Stoop et al., 2008). Approximately $75 \%$ of the saturated fatty acids, namely C14:0 and C16:0, are associated with increased low-density lipoprotein cholesterol levels (German and Dillard, 2006), which in turn are associated with increased risk of cardiovascular disease (Cohen et al., 2006). Commercial initiatives to market milk with a $20 \%$ increase in the amount of unsaturated fatty acids have recently been implemented (Campina, 2007). Detailed milk fat composition can be determined using gas chromatography (GC). This is an accurate but expensive method and, therefore, not suitable for routine milk recording. Changing focus in the dairy industry from fat content or yield toward fat composition requires a fast, inexpensive, and accurate method for quantification of fat composition.

Recently, Soyeurt et al. (2006) showed the potential of Fourier transform infrared spectroscopy (FTIR) for the prediction of detailed milk fat composition. Their results show that fatty acids present in high concentrations especially can be predicted with moderate accuracy with the aid of FTIR. The results of Soyeurt et al. (2006) appear very promising; however, their prediction equations were based on only a limited number of milk samples $(\mathrm{n}=49)$. Furthermore, samples included in the latter study were collected during a limited time frame. Substantial differences in milk fat composition exist between seasons (Stoop, 2009), which might influence the predictability of milk fat composition.

The aim of this study was to verify whether the accuracy of predicting milk fat composition with the aid of FTIR can be improved by the use of a large number of observations. Furthermore, we wanted to quantify the sensitivity of the prediction equations to seasonal variation in fat composition. 


\section{MATERIALS AND METHODS}

\section{Data}

In total, 3,660 milk samples $(0.5 \mathrm{~L}$ each) were collected from individual cows at 1 morning milking. Of these samples, 1,834 samples were collected between February and March 2005 and are referred to as winter samples, and 1,826 samples were collected between May and June 2005 and are referred to as summer samples. Milk samples were transported at $4^{\circ} \mathrm{C}$ and milk fat was extracted on the day of sampling from approximately 400 $\mathrm{mL}$ of milk according to ISO standard 15884 (ISO-IDF, 2002a). Fatty acid methyl esters were prepared from milk fat as described in ISO standard 15884 (ISO-IDF, 2002a) and were analyzed according to ISO standard 15885 (ISO-IDF, 2002b) on a trace GC Ultra chromatograph (Thermo Electron Corporation, Waltham, MA) using a Varian Fame Select column $(100 \mathrm{~m} \times 0.25 \mathrm{~mm}$ i.d.; Varian Inc., Palo Alto, CA). The initial temperature was held at $70^{\circ} \mathrm{C}$ for $1 \mathrm{~min}$, increased to $225^{\circ} \mathrm{C}$ at $3^{\circ} \mathrm{C} / \mathrm{min}$, and held at $225^{\circ} \mathrm{C}$ for $5 \mathrm{~min}$. A volume of $1 \mu \mathrm{L}$ was injected. All peaks were identified and quantified using pure methyl esters (Sigma-Aldrich, Zwijndrecht, the Netherlands; Larodan, Malmo, Sweden).

Fourier transform infrared absorption spectra for 10$\mathrm{mL}$ milk subsamples were recorded using MilkoScan FT 6000 equipment (Foss, Hillerød, Denmark) at the certified laboratory of the Milk Control Station (Zutphen, the Netherlands). The FTIR spectra consisted of 1,060 infrared frequencies (wavenumbers) ranging from 925 to $5,008 \mathrm{~cm}^{-1}$. Part of the GC data used in the current study was used earlier to estimate genetic parameters (Stoop et al., 2008).

\section{Modeling}

The GC data were first graphically inspected for the presence of outliers. Thirty-eight observations were identified as outliers and discarded. The data set for statistical analysis therefore consisted of 3,622 observations in total (winter $=1,822$; summer $=1,804$ ). Descriptive statistics for the data are presented in Table 1. The following fatty acids were modeled: the even-numbered fatty acids C4:0 to C18:0; 5 identified C18:1 isomers; C18:2 cis-9,12; C18:3 cis-9,12,15; and conjugated linoleic acid (i.e., C18:2 cis-9, trans-11). Furthermore, groups of fatty acids were defined according to their assumed effect on human health (German and Dillard, 2006; Table 1): C6-C12, containing C6:0, C8:0, C10:0, and $\mathrm{C} 12: 0$, all assumed to have a neutral effect; C4-C16, containing C14:0 and C16:0, both assumed to have a negative effect; and $\mathbf{C 1 8 u}$, containing all unsaturated $\mathrm{C} 18$ that were part of the data set, assumed to have a positive effect. The amount of saturated and unsaturated fatty acids and their ratio was determined including several odd-numbered saturated fatty acids (C5:0-C17:0) and the even-numbered monounsaturated fatty acids (C10:1-C16:1). The ratio of saturated to unsaturated fatty acids was included in the category "groups of fatty acids." Prior to modeling, GC data of all individual fatty acids and groups of fatty acids were rescaled to a mean of 0 and a standard deviation of 1 . To model relationships between and among GC (dependent) and FTIR (independent) variables, partial least squares regression implemented in the $\mathrm{R}(\mathrm{R}$ Development Core Team, 2008) package PLS (Mevik and Wherens, 2007) was used. The available data were randomly split into 2 parts that had an equal number of observations: 1 part for model calibration and 1 part for model validation. We applied the variable selection strategy of Höskuldsson (2001) to omit irrelevant independent variables. In our study, independent variables (wavenumbers) were ordered according to their average correlation to the dependent variables (GC fatty acids) expressed on a fat basis (g/100 g). This was to ensure that interference of wavenumbers associated with fat percentage was limited. Subsequently, the 200 highest correlated wavenumbers were selected for modeling. These wavenumbers were also used when fatty acids were expressed on a milk basis $(\mathrm{g} / \mathrm{dL})$. The number of latent variables was determined by means of cross validation in the calibration data set.

Five modeling scenarios were performed: 1) calibration in half of all data and validation in the other half of all data (AA); 2) calibration in half of the winter data and validation in the other half of the winter data (WW); 3) validation of the model from scenario WW in all summer data (WS); 4) calibration in half of the summer data and validation in the other half of the summer data (SS); and 5) validation of the model from scenario SS in all winter data $(\mathbf{S W})$. An overview of these scenarios, the number of observations, and selected and latent variables for modeling is presented in Table 2.

For all models, coefficients of determination (validation $r^{2}$ ) of test data sets were calculated as squared correlations between the FTIR and GC values. In addition, prediction bias was calculated as the difference of the means of FTIR and GC values and was expressed as a percentage.

\section{RESULTS AND DISCUSSION}

\section{Modeling Milk Fat Composition}

In Figure 1A, the wavenumbers that were selected for modeling in the AA scenario (i.e., where all data 
Table 1. Mean and SD of individual and groups of fatty acids expressed on the basis of milk and fat

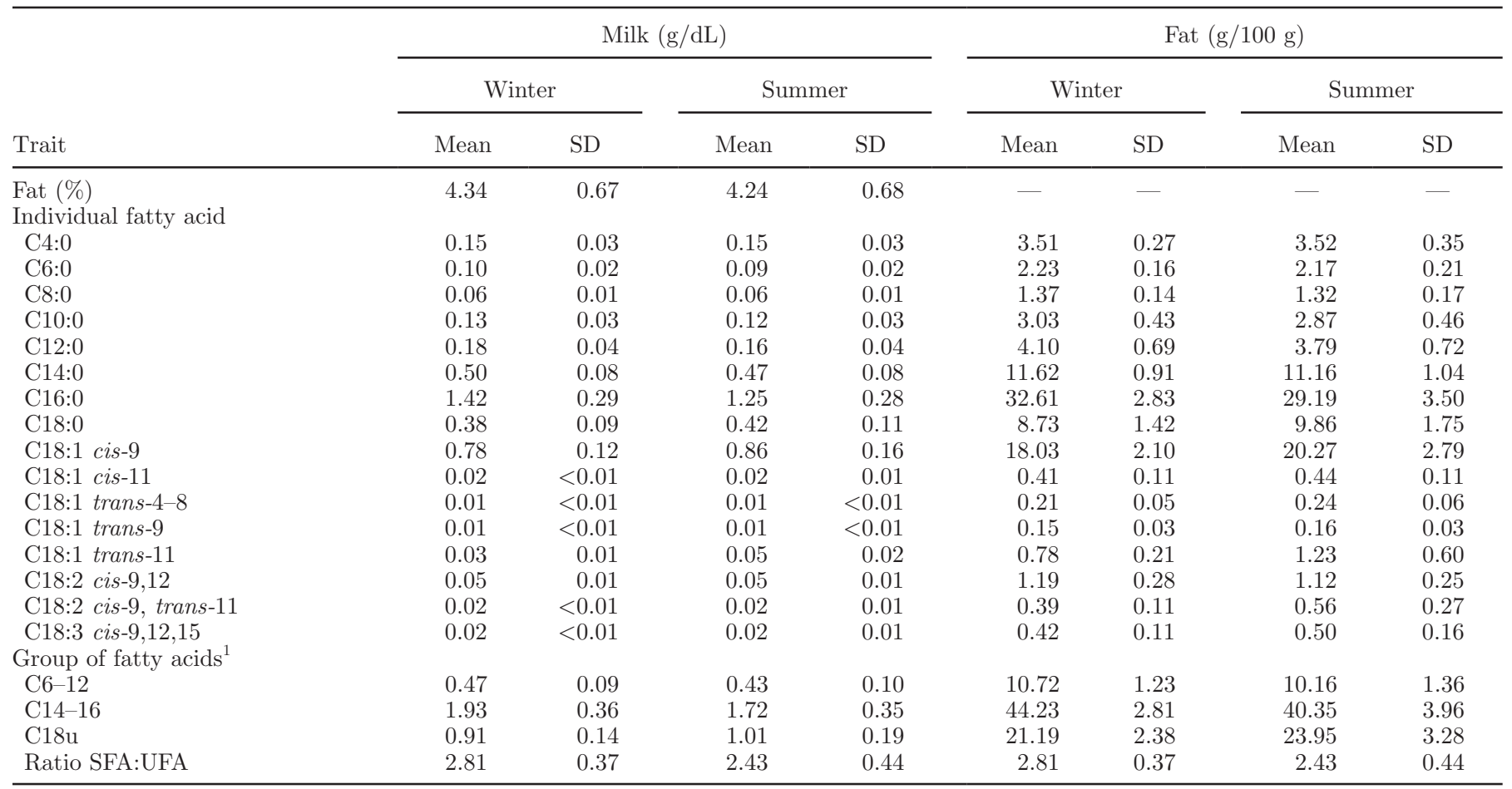

${ }^{1} \mathrm{C} 6-\mathrm{C} 12=\mathrm{C} 6: 0, \mathrm{C} 8: 0, \mathrm{C} 10: 0$, and $\mathrm{C} 12: 0 ; \mathrm{C} 14-\mathrm{C} 16=\mathrm{C} 14: 0$ and $\mathrm{C} 16: 0 ; \mathrm{C} 18 \mathrm{u}=$ all unsaturated $\mathrm{C} 18$ that were part of the data set; ratio SFA:UFA $=$ ratio of saturated fatty acids to unsaturated fatty acids.

was used) are presented. Among others, these include wavenumbers ranging from 2,500 to $3,000 \mathrm{~cm}^{-1}$, which are associated with fatty acids in milk (Soyeurt et al., 2006), and approximately $1,748 \mathrm{~cm}^{-1}$, which is the carbonyl absorption peak of milk fat (Biggs, 1967). The other selected wavenumbers, between approximately 1,050 and $1,600 \mathrm{~cm}^{-1}$, are often associated with several specific chemical bonds in FTIR analyses of, for example, butter and oils.

The results of modeling scenario AA are presented in Table 3. For the individual fatty acids C4:0 to C18:1 cis-9 expressed in grams per deciliter in scenario AA, $\mathrm{r}^{2}$ ranged from 0.82 to 0.96 . The $\mathrm{r}^{2}$ values for other individual fatty acids were considerably lower $(<0.63)$, whereas for groups of fatty acids, $r^{2}$ values were high $(>0.91)$. When expressed as grams per 100 grams in scenario AA, $\mathrm{r}^{2}$ values for $\mathrm{C} 4: 0$ to $\mathrm{C} 18: 1$ cis-9 ranged from 0.51 to 0.84 . The other individual fatty acids showed the same results as on milk basis: intermediate to low $\mathrm{r}^{2}$ values $(<0.57)$ for $\mathrm{C} 18: 1 \mathrm{cis}-11$ to $\mathrm{C} 18: 3$ cis-9,12,15, but somewhat lower $\mathrm{r}^{2}$ values $(>0.77)$ for groups of fatty acids. These results show that important individual fatty acids associated with human health (C14:0 and C16:0; German and Dillard, 2006) can be

Table 2. Scenarios, the number of observations used for calibration and validation, the number of selected variables $(\mathrm{SV})$, and the number of latent variables (LV)

\begin{tabular}{|c|c|c|c|c|c|c|}
\hline \multirow[b]{2}{*}{ Scenario $^{1}$} & \multirow[b]{2}{*}{ Calibration (n) } & \multirow[b]{2}{*}{ Validation (n) } & \multicolumn{2}{|c|}{ Milk (g/dL) } & \multicolumn{2}{|c|}{ Fat $(\mathrm{g} / 100 \mathrm{~g})$} \\
\hline & & & $\mathrm{SV}(\mathrm{n})$ & $\mathrm{LV}(\mathrm{n})$ & SV (n) & $\mathrm{LV}(\mathrm{n})$ \\
\hline AA & 1,811 & 1,811 & 200 & 20 & 200 & 40 \\
\hline WW & 909 & 909 & 200 & 10 & 200 & 20 \\
\hline WS & 909 & 1,804 & 200 & 10 & 200 & 20 \\
\hline SS & 902 & 902 & 200 & 10 & 200 & 20 \\
\hline SW & 902 & 1,818 & 200 & 10 & 200 & 20 \\
\hline
\end{tabular}

${ }^{1} \mathrm{AA}=$ calibration in half of all data and validation in the other half of all data; $\mathrm{WW}=$ calibration in half of the winter data and validation in the other half of the winter data; WS = validation of the model from scenario WW in all summer data; SS = calibration in half of the summer data and validation in the other half of the summer data; SW = validation of the model from scenario SS in all winter data. 


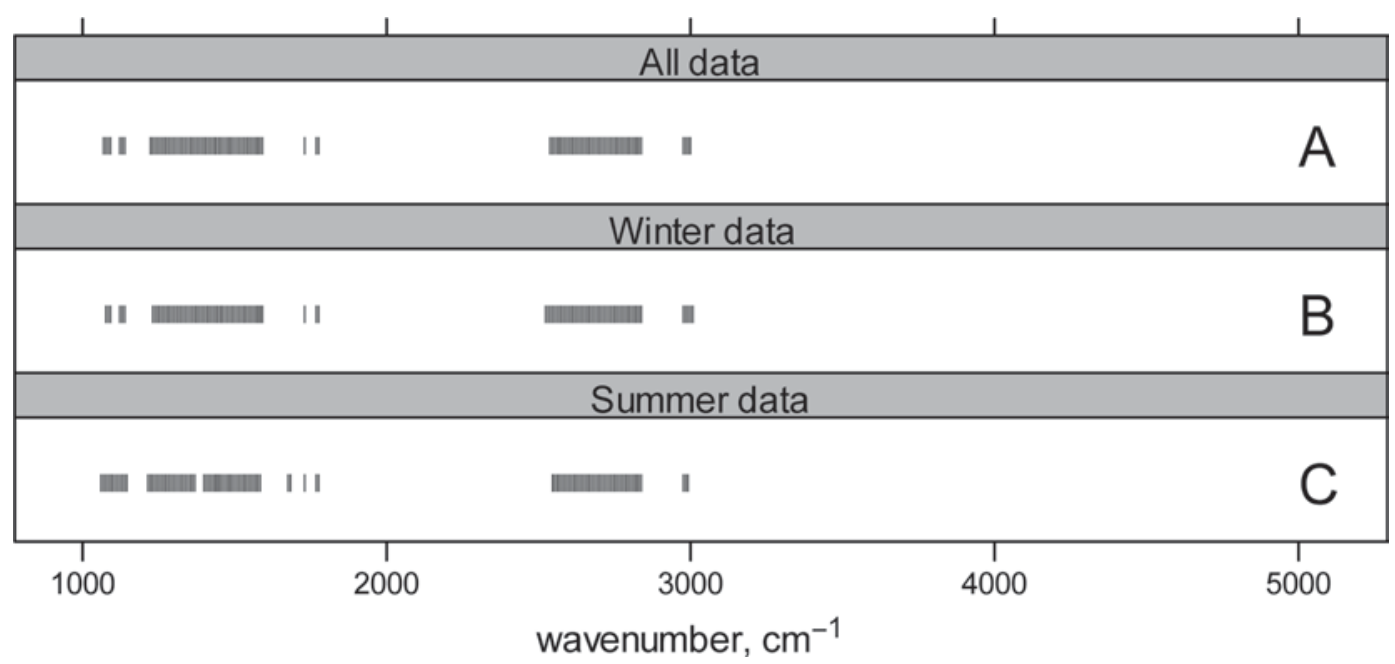

Figure 1. Wavenumbers selected for modeling of milk fat composition in A) scenario AA (calibration in half of all data and validation in the other half of all data); B) scenario WW (calibration in half of the winter data and validation in the other half of the winter data); and C) scenario SS (calibration in half of the summer data and validation in the other half of the summer data).

accurately predicted based on FTIR. The $\mathrm{r}^{2}$ value for both C14:0 and C16:0 was equal to 0.94 when expressed on a milk basis $(\mathrm{g} / \mathrm{dL})$, and 0.73 for $\mathrm{C} 14: 0$ and 0.71 for C16:0 when expressed on a fat basis (g/100 g). For the ratio of saturated fatty acids to unsaturated fatty acids, $\mathrm{r}^{2}$ value was 0.91 when expressed on milk basis and 0.87 when expressed on fat basis. Therefore, prediction of fatty acid composition based on FTIR enables the dairy industry to routinely measure C14:0, C16:0, and the ratio of saturated to unsaturated fatty acids in tank milk or milk of individual cows in an inexpensive and accurate way. This can be an important step toward the development of specialized products with respect to milk fat composition. Milk with an increased amount of unsaturated fatty acids currently sold in the Netherlands (Campina, 2007) is an example of this. Another potential application is the monitoring of a cow's health status; Van Haelst et al. (2008) reported that C18:1 cis-9 can be used as an early predictor of ketosis. Results of the current study show that C18:1 cis-9 can be predicted with an $\mathrm{r}^{2}$ value $>0.84$ based on FTIR (AA scenario; Table 3).

\section{Relationship Between Fatty Acid Concentration and $r^{2}$}

Figures $2 \mathrm{~A}$ and $2 \mathrm{~B}$ show strong relationships between fatty acid concentration and modeling success, which was previously mentioned by Soyeurt et al. (2006). Log-linear regression lines are plotted to further visualize this relationship; we ignored the fact that one of the regression lines does exceed $r^{2}=1$. Soyeurt et al. (2006) used the quantity RPD (ratio of prediction to deviation $)=$ standard deviation $(\mathrm{SD}) /$ standard error of cross-validation (SECV) as an indicator of modeling success. Because we do not give cross validation results in this paper, we derived RPD from the following expression:

$$
\mathrm{RPD}^{2}=\mathrm{SD}^{2} / \mathrm{SECV}^{2} \text {. }
$$

Assuming that $\mathrm{SD}^{2}=\operatorname{Var}_{\mathrm{p}}$ (i.e., the total variance of a given trait), and $\mathrm{SECV}^{2}=\operatorname{Var}_{\mathrm{e}}$ (i.e., the residual variance after modeling this given trait), we can rewrite this expression as

$$
\begin{gathered}
\operatorname{RPD}^{2}=\operatorname{Var}_{\mathrm{p}} / \operatorname{Var}_{\mathrm{e}}= \\
\operatorname{Var}_{\mathrm{p}} /\left[\left(1-\mathrm{r}^{2}\right) \times \operatorname{Var}_{\mathrm{p}}\right]=\left(1-\mathrm{r}^{2}\right)^{-1} .
\end{gathered}
$$

Taking the square root of the latter expression results in

$$
\mathrm{RPD}=\left(1-\mathrm{r}^{2}\right)^{-0.5}
$$

The relationship between fatty acid concentration and $\mathrm{RPD}$ is plotted in Figures $2 \mathrm{C}$ and $2 \mathrm{D}$. The regression coefficient in Figure $2 \mathrm{C}$ of 2.945 is much higher than the regression coefficient presented by Soyeurt et al. (2006; 0.7301). In this study we used a large data set, and decreasing the amount of data in the AA scenario did not decrease $r^{2}$ values dramatically. Therefore, our results may actually give upper limits of modeling success. The presented regression equations indicate, for example, that a desired $\mathrm{r}^{2}$ value of 0.8 or higher is on average achievable for fatty acids with a concentration 
Table 3. Validation coefficients of determination $\left(\mathrm{r}^{2}\right)$ for individual and groups of fatty acids expressed on the basis of milk and fat for all scenarios ${ }^{1}$

\begin{tabular}{|c|c|c|c|c|c|c|c|c|c|c|}
\hline Trait & \multicolumn{5}{|c|}{ Milk (g/dL) } & \multicolumn{5}{|c|}{ Fat $(\mathrm{g} / 100 \mathrm{~g})$} \\
\hline \multicolumn{11}{|l|}{ Individual fatty acid } \\
\hline $\mathrm{C} 4: 0$ & 0.91 & 0.83 & 0.78 & 0.77 & 0.82 & 0.55 & 0.51 & 0.39 & 0.42 & 0.50 \\
\hline C6:0 & 0.96 & 0.89 & 0.89 & 0.89 & 0.90 & 0.73 & 0.63 & 0.60 & 0.71 & 0.58 \\
\hline C8:0 & 0.94 & 0.85 & 0.84 & 0.84 & 0.85 & 0.73 & 0.60 & 0.53 & 0.61 & 0.56 \\
\hline C10:0 & 0.92 & 0.75 & 0.81 & 0.81 & 0.76 & 0.75 & 0.57 & 0.59 & 0.65 & 0.56 \\
\hline C16:0 & 0.94 & 0.85 & 0.75 & 0.79 & 0.83 & 0.71 & 0.36 & 0.53 & 0.65 & 0.36 \\
\hline C18:0 & 0.82 & 0.58 & 0.64 & 0.70 & 0.59 & 0.51 & 0.31 & 0.31 & 0.43 & 0.32 \\
\hline C18:1 cis-9 & 0.92 & 0.69 & 0.79 & 0.81 & 0.68 & 0.84 & 0.66 & 0.80 & 0.80 & 0.66 \\
\hline C18:1 cis-11 & 0.27 & 0.18 & 0.15 & 0.23 & 0.12 & 0.22 & 0.19 & 0.14 & 0.14 & 0.11 \\
\hline C18:1 trans $-4-8$ & 0.48 & 0.23 & 0.13 & 0.20 & 0.15 & 0.40 & 0.23 & 0.24 & 0.33 & 0.22 \\
\hline C18:1 trans-9 & 0.53 & 0.32 & 0.27 & 0.29 & 0.27 & 0.42 & 0.25 & 0.36 & 0.38 & 0.22 \\
\hline C18:1 trans-11 & 0.63 & 0.26 & 0.09 & 0.17 & 0.18 & 0.57 & 0.26 & 0.27 & 0.41 & 0.24 \\
\hline C14-16 & 0.97 & 0.90 & 0.81 & 0.85 & 0.89 & 0.77 & 0.45 & 0.67 & 0.74 & 0.46 \\
\hline $\mathrm{C} 18 \mathrm{u}$ & 0.94 & 0.69 & 0.77 & 0.80 & 0.68 & 0.87 & 0.70 & 0.85 & 0.86 & 0.69 \\
\hline Ratio SFA:UFA & 0.91 & 0.43 & 0.65 & 0.59 & 0.38 & 0.87 & 0.72 & 0.84 & 0.85 & 0.68 \\
\hline
\end{tabular}

${ }^{1} \mathrm{AA}=$ calibration in half of all data and validation in the other half of all data; $\mathrm{WW}=$ calibration in half of the winter data and validation in the other half of the winter data; WS = validation of the model from scenario WW in all summer data; SS = calibration in half of the summer data and validation in the other half of the summer data; SW = validation of the model from scenario SS in all winter data.

${ }^{2} \mathrm{C} 6-\mathrm{C} 12=\mathrm{C} 6: 0, \mathrm{C} 8: 0, \mathrm{C} 10: 0$, and $\mathrm{C}: 12.0 ; \mathrm{C} 14-\mathrm{C} 16=\mathrm{C} 14: 0$ and $\mathrm{C} 16: 0 ; \mathrm{C} 18 \mathrm{u}=$ all unsaturated $\mathrm{C} 18$ that were part of the data set; ratio $\mathrm{SFA}: \mathrm{UFA}=$ ratio of saturated fatty acids to unsaturated fatty acids.

of $0.19 \mathrm{~g} / \mathrm{dL}$ or greater. On a fat basis, a desired $\mathrm{r}^{2}$ value of 0.6 or higher is on average achievable for fatty acids with a concentration of $2.45 \mathrm{~g} / 100 \mathrm{~g}$ or greater.

In general, all modeling on the basis of milk $(\mathrm{g} / \mathrm{dL})$ was more accurate than on the basis of fat $(\mathrm{g} / 100 \mathrm{~g})$, which is in agreement with Soyeurt et al. (2006). The latter authors mention that this is caused by the fact that predicting fatty acids on the basis of FTIR is the combined effect of predicting fat content and fat composition. In addition to this, it is important to note that FTIR is performed on milk samples, whereas GC is performed on fat samples, which means that their relationship is affected by the variation in fat percentage.

\section{Effect of Season on Modeling}

In Figures $1 \mathrm{~B}$ and $1 \mathrm{C}$, the wavenumbers that were selected for modeling in the WW and SS scenarios are presented. Wavenumbers selected for modeling in the WW scenario were roughly equal to those used in the AA scenario. The wavenumbers for modeling in the SS scenario were slightly different: wavenumbers around 1,100 and $1,680 \mathrm{~cm}^{-1}$ were present, whereas wavenumbers around $1,400 \mathrm{~cm}^{-1}$ were absent compared with scenarios AA and WW. It is difficult to attribute these differences directly to the fatty acids used in our study. However, percentagewise, the largest differences in levels of fatty acids between winter and summer were found for the unsaturated C18 fatty acids (Table 1), which are discriminated by different chemical bonds or specific chemical bonds in different positions.

Scenarios WS and SW, in which the calibration was based on data of one season and validation was performed in the other season, were used to study the influence of season on validation $r^{2}$. In our case, differences in season implied, among other things, differences in feeding. In winter, cows were housed indoors and were fed silage whereas in summer the majority of cows were grazing on pasture. This is known to have an effect on milk fat composition (Palmquist and Beulieu, 1993; Schroeder et al., 2003; Couvreur et al., 2007). Table 1 shows that fatty acid concentrations differed between seasons. Two-sample $t$-tests (results not shown) indicated that with the exception of $\mathrm{C} 4: 0$ (g per $100 \mathrm{~g}$; $P$ $=0.265$ ), all individual fatty acids and groups of fatty acids differed significantly $(P<0.001)$ between the winter and the summer season. The $\mathrm{r}^{2}$ values obtained within scenarios WW, WS, SS, and SW are presented in Table 3. Comparing scenarios WW and SS with sce- 

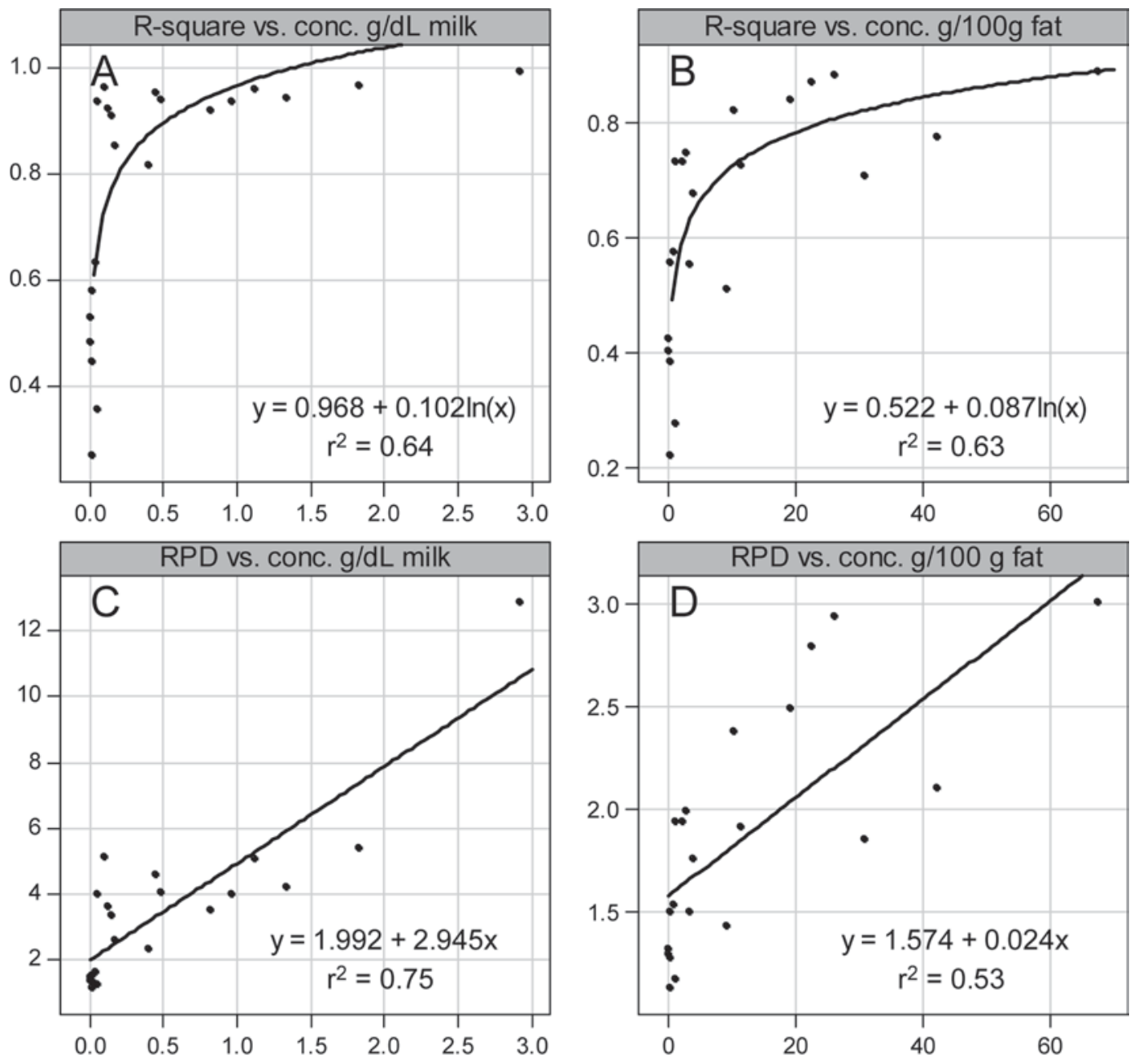

Fatty acid concentration

Figure 2. The relationship of concentration (conc) of individual and groups of fatty acids and modeling success expressed as A) grams per deciliter versus $\mathrm{r}^{2}$; B) grams per $100 \mathrm{~g}$ versus $\mathrm{r}^{2}$; C) grams per deciliter versus RPD (ratio of prediction to deviation); and D) grams per $100 \mathrm{~g}$ versus RPD. RPD $=\left(1-\mathrm{r}^{2}\right)^{-0.5}$. Because ratio of saturated fatty acids (SFA) to unsaturated fatty acids (UFA) cannot be said to have a concentration, the dots for ratio SFA:UFA were replaced by separate dots for SFA and UFA.

nario AA shows that $\mathrm{r}^{2}$ values were lower. This effect was more pronounced for the minor fatty acids (C18:1 cis-11-C18:3 cis-9,12,15).

When using the models calibrated on winter and summer data to predict winter data (i.e., comparing scenario WW with $\mathrm{SW}$ ), $\mathrm{r}^{2}$ values were almost equal for the major fatty acids and groups of fatty acids and somewhat greater for the minor fatty acids on milk basis. On a fat basis, $r^{2}$ values of scenarios $\mathrm{WW}$ and SW differed only slightly. Therefore, despite the use of a model calibrated on summer data to predict winter data, $\mathrm{r}^{2}$ values were in general very similar. The comparison of scenarios SS and WS (i.e., the models calibrated on winter and summer data to predict summer data) showed a similar picture: small differences were observed for the major fatty acids and groups of fatty acids when expressed on a milk basis. Expressed on a fat basis, the differences were somewhat greater. Therefore, the model calibrated on winter data to predict summer data also showed marginal differences in $\mathrm{r}^{2}$ values.

\section{Prediction Bias}

Prediction bias was generally low in scenario AA, ranging from 0 to $3.3 \%$ whether expressed as grams per deciliter or grams per 100 grams (Table 4). For scenarios WW and SS, the same conclusion could be drawn for the major fatty acids (C4:0-C18:1 cis-9) and groups of fatty acids $(0-1.9 \%)$. In scenarios WW and SS, minor 
Table 4. Percentage prediction bias $^{1}$ of individual and groups of fatty acids (expressed on the basis of milk and fat) for all scenarios ${ }^{2}$

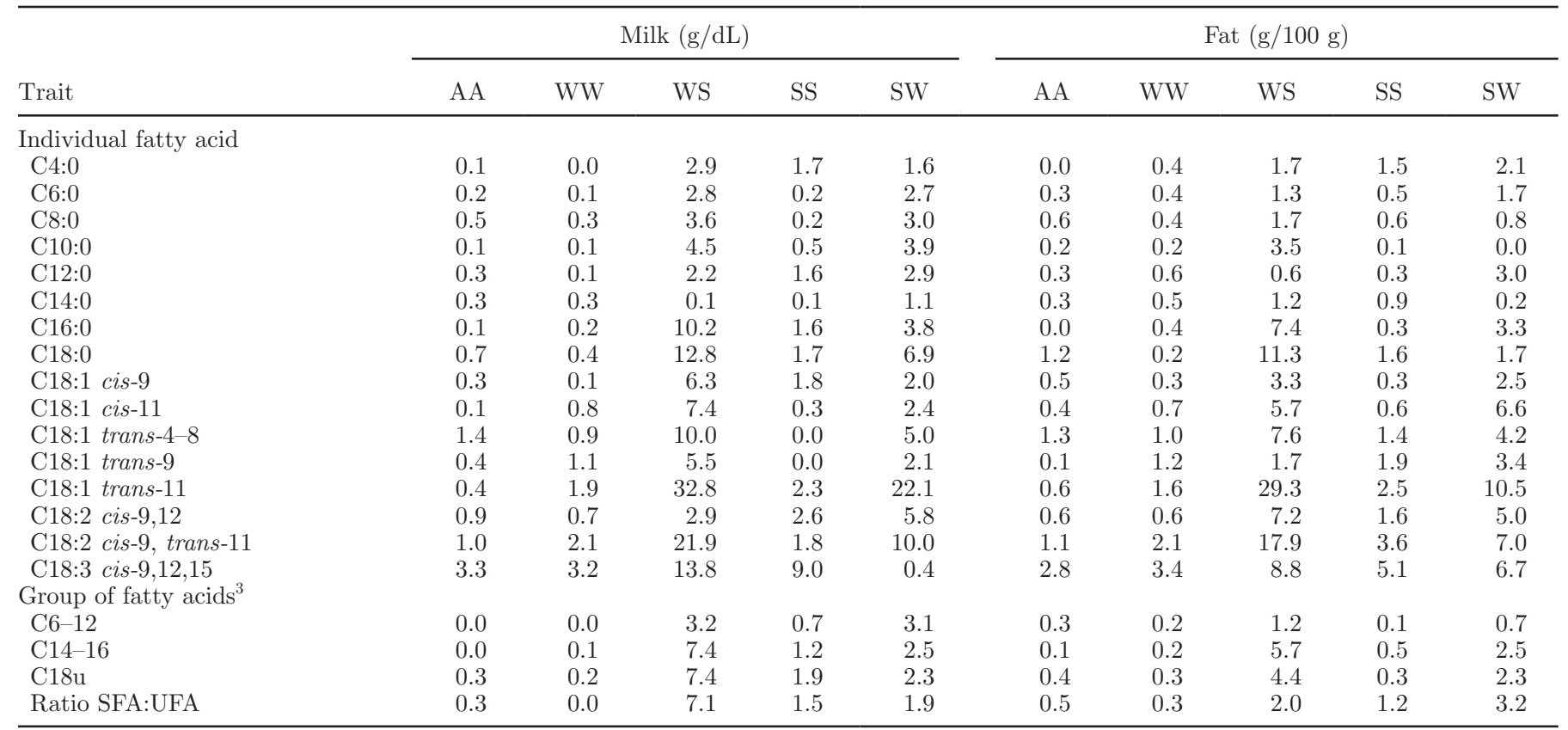

${ }^{1}$ Absolute value (bias/mean) $\times 100$.

${ }^{2} \mathrm{AA}=$ calibration in half of all data and validation in the other half of all data; $\mathrm{WW}=$ calibration in half of the winter data and validation in the other half of the winter data; WS = validation of the model from scenario WW in all summer data; SS = calibration in half of the summer data and validation in the other half of the summer data; $\mathrm{SW}=$ validation of the model from scenario SS in all winter data.

${ }^{3} \mathrm{C} 6-\mathrm{C} 12=\mathrm{C} 6: 0, \mathrm{C} 8: 0, \mathrm{C} 10: 0$, and $\mathrm{C} 12: 0 ; \mathrm{C} 14-\mathrm{C} 16=\mathrm{C} 14: 0$ and $\mathrm{C} 16: 0 ; \mathrm{C} 18 \mathrm{u}=$ all unsaturated C18 that were part of the data set; ratio SFA:UFA $=$ ratio of saturated fatty acids to unsaturated fatty acids.

fatty acids showed somewhat higher prediction bias in general (0-3.6\%), with one extreme value for C18:3 cis-9,12,15 (9.0\%). For scenarios WS and SW, prediction bias was higher, especially on the basis of milk, and some fatty acids (e.g., C18:1 trans-11) were highly biased. Large prediction bias was observed 1) generally when fatty acids were present in low concentrations (i.e., bad predictability); for example, C18:1 trans-11; and 2) when the difference in mean and standard deviation between winter and summer samples was large (e.g., C16:0, C18:0, C18:1 trans-11, and C18:2 cis-9, trans-11). Whether bias would compromise the use of these models, however, depends on the application. If absolute values are required, bias is problematic. On the other hand, where interest is in differences between individuals (e.g., genetic analysis), bias seems to be less of a severe problem.

\section{CONCLUSIONS}

The main conclusion from our research is that the use of many observations does increase predictability of milk fat composition based on infrared spectroscopy. However, for fatty acids with low concentrations, the use of many observations does not increase predictabil- ity to a level at which practical application becomes obvious. Furthermore, we conclude that the effect of season was limited on validation $\mathrm{r}^{2}$ but was occasionally large on prediction bias. For fatty acids that showed large differences in level and standard deviation between winter and summer, a representative sample including observations collected in various seasons is critical for unbiased prediction. This research showed that all major fatty acids, combined groups of fatty acids, and the ratio of saturated to unsaturated fatty acids could be predicted accurately and that infrared spectroscopy therefore provides a means for the dairy industry and breeding organizations to work toward dairy products that support human health.

\section{ACKNOWLEDGMENTS}

This study was part of the Milk Genomics Initiative and the project "Melk op maat," funded by Wageningen University (Wageningen, the Netherlands), the Dutch Dairy Association (NZO, Zoetermeer, the Netherlands), CRV (cooperative cattle improvement organization, Arnhem, the Netherlands), the Dutch Technology Foundation (STW, Utrecht, the Netherlands), the Dutch Ministry of Economic Affairs (The Hague, the 
Netherlands), and the provinces of Gelderland (Arnhem) and Overijssel (Zwolle, the Netherlands). The authors acknowledge the participating herd owners, the Dutch Milk Control Station (Qlip, Zutphen, the Netherlands), and H. van der Bijgaart (Qlip), and Foss (Hillerød, Denmark) for decryption of infrared data.

\section{REFERENCES}

Biggs, D. A. 1967. Milk analysis with the infrared milk analyzer. J. Dairy Sci. 50:799-803.

Campina. 2007. Campina milk with a more balanced fatty acid composition. http://www.en.frieslandcampina.com Accessed Sept. 25,2009 .

Cohen, J. C., E. Boerwinkle, T. H. Mosley, and H. H. Hobbs. 2006. Sequence variation in $P C S K 9$, low LDL, and protection against coronary heart disease. N. Engl. J. Med. 354:1264-1272.

Couvreur, S., C. Hurtaud, P. G. Marnet, P. Faverdin, and J. L. Peyraud. 2007. Composition of milk fat from cows selected for milk fat globule size and offered either fresh pasture or a corn silage-based diet. J. Dairy Sci. 90:392-403.

Foss. 2009. MilkoScan FT+ Technical Specifications. http://www. foss.dk/Solutions/ProductsDirect/MilkoScanftplus/Technical\%20 specifications.aspx Accessed May 14, 2009.

German, J. B., and C. J. Dillard. 2006. Composition, structure and absorption of milk lipids: A source of energy, fat-soluble nutrients and bioactive molecules. Crit. Rev. Food Sci. Nutr. 46:57-92.

German, J. B., R. A. Gibson, R. M. Krauss, P. Nestel, B. Lamarche, W. A. van Staveren, J. M. Steijns, L. C. P. G. M. de Groot, A. L. Lock, and F. Destaillats. 2009. A reappraisal of the impact of dairy foods and milk fat on cardiovascular disease risk. Eur. J. Nutr. 48:191-203.

Höskuldsson, A. 2001. Variable and subset selection in PLS regression. Chemom. Intell. Lab. Syst. 55:23-38.
ISO-IDF. 2002a. Milkfat-Preparation of fatty acid methyl esters. ISO 15884 IDF 182. International Dairy Federation, Brussels, Belgium.

ISO-IDF. 2002b. Milkfat-Determination of the fatty acid composition by gas-liquid chromatography. ISO 15885-IDF 184 . International Dairy Federation, Brussels, Belgium.

Mevik, B. H., and R. Wherens. 2007. The PLS package: Principal component and partial least squares regression in R. J. Stat. Softw. 18:1-24.

Miglior, F., B. L. Muir, and B. J. Van Doormaal. 2005. Selection indices in Holstein cattle of various countries. J. Dairy Sci. 88:1255-1263.

Palmquist, D. L., and A. D. Beulieu. 1993. Feed and animal factors influencing milk fat composition. J. Dairy Sci. 76:1753-1771.

R Development Core Team. 2008. R: A language and environment for statistical computing. R Foundation for Statistical Computing, Vienna, Austria.

Schroeder, G. F., J. E. Delahoy, I. Vidaurreta, F. Bargo, G. A Gagliostro, and L. D. Muller. 2003. Milk fatty acid composition of cows fed a total mixed ration or pasture plus concentrates replacing corn with fat. J. Dairy Sci. 86:3237-3248.

Soyeurt, H., P. Dardenne, F. Dehareng, G. Lognay, D. Veselko, M. Marlier, C. Bertozzi, P. Mayeres, and N. Gengler. 2006. Estimating fatty acid content in cow milk using mid-infrared spectrometry. J. Dairy Sci. 89:3690-3695.

Stoop, W. M. 2009. Genetic variation in bovine milk fat composition. $\mathrm{PhD}$ thesis, Wageningen University, the Netherlands. http:// edepot.wur.nl/3306.

Stoop, W. M., J. A. M. van Arendonk, J. M. L. Heck, H. J. F. van Valenberg, and H. Bovenhuis. 2008. Genetic parameters for major milk fatty acids and milk production traits of Dutch HolsteinFriesians. J. Dairy Sci. 91:385-394.

Van Haelst, Y. N. T., A. Beeckman, A. T. M. van Knegsel, and V. Fievez. 2008. Short communication: Elevated concentrations of oleic acid and long-chain fatty acids in milk fat of multiparous subclinical ketotic cows. J. Dairy Sci. 91:4683-4686. 